\title{
OPTIMIZATION OF PRODUCTION RESOURCES, THE EFFECTIVE FUNCTIONING OF SMALL FARM PATTERNS
}

\author{
INNA KUZNETSOVA \\ Saratov state technical university, Russia
}

\section{ABSTRACT}

The article proves that any commercial farm unit may become commercially viable and economically promising, on the basis of one's own current capabilities. A methodology is proposed for small farm patterns that allow to optimize their resources provision both from the point of view of the solution of a task to a maximum of gross income and during the statement of the problem on the economical payback of additional involvement of basic production resources.

\section{JEL CLASSIFICATION \& KEYWORDS}

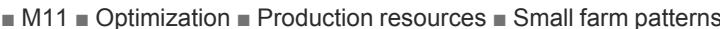
- Marginal analysis

\section{INTRODUCTION}

Despite the signs of stabilization, outlined in the present time in the Russian economy, there is constant strategic threat to the development of agriculture. First of all, it is connected with the lack of essential scientific developments for small farm patterns. Hence, most of the beginning farmers are forced to work, relying on their own experience, often intuitively and haphazardly. Because of that, production programs and resources formed by them, in the majority of cases do not correspond to the actual proportion of the workers on the particular farming area. Equipment and other means of production are often purchased not for a specific program, but on the basis of available opportunities, "in reserve".

Given that the role of small farm patterns in the life of the modern Russian village remains and will continue to be very high, traditionally the capital-intensive way of their development in connection with the present investment opportunities is unreal. Nevertheless, proceeding from the already existing capacity, any farm unit may become a competitive and economically promising, if thorough substantiation of the parameters of its resource potential is carried out. Due to the high dynamics, the maneuverability, the competitive nature of small farm patterns, it is almost constantly possible to make adjustments in their productive activity with the purpose of increasing of its profitability.

Production function for small farm patterns conditions

In a number of works $[1,2]$ we have proved that the production function for small farm patterns conditions describes a multi-factor correlation equation of non-linear type. In general terms it can be presented as an exponential dependence of the type:

$$
F=c^{*} e^{a_{1} x_{1}^{2}+b_{1} x_{1}} \ldots{ }^{*} e^{a_{n} x_{n}^{2}+b_{n} x_{n}},
$$

where $F$ is the gross receipts from sales of agricultural products, thousand rubles;

$\mathrm{n}$ is the number of production factors included in the model; $\mathrm{x}_{1}, \mathrm{x}_{2}, \mathrm{x}_{3}$ - numerical characteristics of productive factors.

The resources used for the creation of agricultural products are usually regarded as a factor of production when considering the production functions. The absence of one or several of them makes the production process impossible. Moreover, factors of production are complementary. The production of any good amid small farm patterns requires land, on which the farm unit is built; assets in the form of equipment, raw materials; the labour of the workers and employees.

The production function may fundamentally include any number of factors, however, as a rule, no more than 2-3 have the real value, and they explain approximately $70-90$ $\%$ of changes of the resulting factor, in our case these are the proceeds from the sale of products.

Changes in any of the factors of production lead to a change in the value of the production function. With the help of the theory of marginal analysis, the aim of which is to establish the conditions for obtaining maximum values of the production function, it is possible to study its behavior when changing certain factors (resources) of production, i.e. to determine the response of the input factors. The most favorable combination of factors of production is not immutable. It depends on the level of the prices of factors of production, the changes in the technical processes and of sizes of production.

Substantiation of optimal resource provision of small farm patterns

As a result of application of the above mentioned methods the optimal resources can be proved both from the point of view of the solution of a task to a maximum of gross income, and in the process of the formulation of the problem of the economic payback from additional attraction of basic production resources. Properly developed mathematical support and software allow you to make necessary calculations with the help of modern personal computers.

Various industrial resources require different duration periods of time for their developments.

In the short term there is a change in individual resource production at fixed values of the others. The ratio between the number of input factors and the result of production in this case (in the presence of others, but fixed on the average level) takes the form:

$$
y_{i}=f\left(x_{i}\right),
$$

where $y_{i}$ is the production output; $x_{i}$ a variable factor, $\mathrm{i} \in\{1, \ldots, \mathrm{n}\}$.

The marginal product $\left(\mathrm{MP}_{\mathrm{i}}\right)$ is a product derived from a change in the total product, caused by the introduction in the production of an additional unit of the $\mathrm{i}$-th variable factor:

$$
M P_{i}=\frac{d\left(f\left(x_{i}\right)\right)}{d x_{i}}=\frac{d(F)}{d x_{i}} .
$$

This value is always positive, as it is impossible to imagine the use of some resource, aimed at reduction of production output.

The total (general) gross domestic product $\left(\mathrm{TP}_{\mathrm{i}}\right)$ is defined as the total volume of production obtained as a result of introduction of the i-th factor in the production. The value of the total product equals the product produced by the first resource, plus the product produced by a second resource, plus, etc. Then the $T P_{i}$ for the value of the resource $x_{i}=x_{k}$ can be defined as: 


$$
T P_{i_{k}}=\int_{0}^{x_{i_{k}}} M P_{i} d x_{i}
$$

The value of the middling $\left(\mathrm{AP}_{\mathrm{i}}\right)$ will be determined as a share of total product per unit of $\mathrm{i}$-th factor (resource). In other words:

$$
A P_{i}=\frac{T P_{i}}{X_{i}}
$$

Analyze the change in the average of the product (AP) areas of growth and decline:

$$
\frac{d(A P)}{d X}=\frac{d\left[\frac{T P}{X}\right]}{d X}=\frac{X \frac{d T P}{d X}-T P}{X^{2}}=\frac{1}{X}\left[\frac{d(T P)}{d X}-\frac{T P}{X}\right]=\frac{1}{X}(M P-A P) .
$$

Which means that, the function AP increases (has a positive derivative), when the MP > AP, otherwise the curve AP decreases. Its maximum value of the function AP takes at this value of $X$, which is performed equality MP $=A P$.

The maximum value of the function MP takes at the point $X=A$, where the derivative is equal to zero:

$$
M P=\frac{d(M P)}{d X}=0 .
$$

But so as $\frac{d(M P)}{d X}=\frac{d^{2}(T P)}{d X^{2}}$, the TP at this point has a bend. In the interval OA function curve TP has a concave character (the second of its derivative is positive), i.e. when one and the same increments $\Delta \mathrm{X}$ on the interval OA increment $\triangle T P$ increasing, and with the continued growth increment $\Delta \mathrm{X}$ increment $\Delta \mathrm{TP}$ reduced: the curve of TP in division $A B$ has the convex form.

This change in the production function reflects the action of one of the fundamental laws of economics is the law of diminishing returns a resource, according to which the increase in units ac resource at the constant size of the permanent will certainly lead to a situation where each subsequent unit of variable resource will add to the total product of less than his previous unit.

The most effective is the increase of the variable resource (X opt), in which the curve of the total gross domestic product reaches its maximum or curve of marginal product takes a value of zero: MP $=0$.

\section{Determination of the point of maximum profit}

In that case, if the value of variable factors were not expressed in terms of value, and in kind (for example, the number of members of the farm or the area of the arable land), it is necessary to define a point of maximum profit. The profit in this case is the difference between the total revenue and the total costs of this resource.

Point of maximum profit will be there, where the total sales proceeds from manufactured products will exceed the costs of the resource to the highest value, or where the tangent to the curve of the total cost of the product is parallel to direct the overall costs of the resource. Up to this point increase in the number of ac resource leads to receiving the so-called "super-profits". Starting from this point, additional revenues from additional units of a resource does not cover additional costs. The maximum profit is the case in point, where the costs of alternating resource equal to the value of the marginal product.

Determine the change of any of the resources is the most effective, can be on the basis of the analysis of the obtained numerical and graphical illustrations. The least expensive will be the change of the resource, in which the return on invested ruble will be the greatest.

\section{Intensive and extensive way of development of small} forms of managing

As demonstrated by in our previous calculations [1, 3] on the value of the total gross revenue of the most significant impact of the arable land: with the increase of arable land increases the total gross revenue also increases. Such a way of development of agriculture is extensive. He is currently the least expensive and therefore it is most often used by farmers. But, naturally, increase of output of products through the use of an additional area of arable land is only possible up to a certain limit.

Intensive path of development of small forms of the economy is characterized by the amount spent on unit of the area of labour and capital. And the more labour and capital inputs per unit area, the more intense is being produced. The higher the level of intensity of matches, as a rule, higher production output. Naturally, this statement is true only up to a certain limit.

\section{Conclusion}

Thus, the least costly and the most reasonable in the conditions of functioning of small forms of farming will be a change in the resource, where returns on invested ruble will be the greatest.

Conducted by the author's research in a number of peasant (farmers') and personal (household) farms allow to speak about that for the small forms of managing it is quite possible use of the concept of production function and the mechanism of calculation of its parameters is traditional. Given the practical benefit, which they bring to the model of production functions specific agricultural enterprises in terms of choice of the strategy of their development, it makes sense to develop research in this area through the use of as a factor signs of other resource indicators, and the quality of the production function - other dependencies, for example, a logistic type.

\section{REFERENCES}

1. Kuznetsova I. V. Optimization of resource provision of personal subsidiary farms. IN. Kuznetsova E. N. Borodina // Bulletin of the development of science and education. - M.: NAUKA, 2007. - № 2.

2. Kuznetsova I.V. The direction of the effective functioning of small forms of farming / I. V. Kuznetsova, N. S. Tjurina //Innovative methods and technologies in science and economy: Anniversary collection of scientific works, devoted to the 10-th anniversary of the department of inform-x systems and technologies.- Engels: RIC SIC, 2010.

3. Sazonov C. N., Sazonova D. D., Kuznetsova I. V. -Methodology of substantiation of the resource support for peasant (farm) // Economic-mathematical methods in the agro-industrial complex: history and prospects. Materials of the international scientific symposium devoted to the memory Kravchenko In. G. - M., 1999. 